\title{
SURGERY FOR MITRAL VALVE DISEASE IN THE PEDIATRIC AGE GROUP
}

Naoki Yoshimura, MD

Masahiro Yamaguchi, MD

Yoshihiro Oshima, MD

Shigeteru Oka, MDa

Yoshio Ootaki, MDa

Hirohisa Murakami, MD

Teruo Tei, MD $^{\mathrm{b}}$

Kyoichi Ogawa, MDa
Objectives: We reviewed a 20-year experience with the surgical treatment of mitral valve disease in the pediatric age group at our institution with 2 objectives: to clarify the long-term results over the last 2 decades and to evaluate the recent advances in mitral valve operation in children. Methods: Since December 1978, 56 patients have undergone a total of 36 mitral valve repairs and 30 mitral valve replacements. Associated cardiac anomalies were present in 46 patients $(82 \%)$, and concurrent repair of associated lesions was performed in 37 patients $(66 \%)$. The age of the patients ranged from 3 months to 15 years (mean, 3.6 years) at mitral valve repair, and ranged from 2 months to 16 years (mean, 5.7 years) at mitral valve replacement. Mean follow-up period was 92.0 months (range, 1-235 months). Results: There were 2 hospital deaths and 2 late deaths in patients who underwent mitral valve repair. Reoperation was performed in 4 patients. Three of these patients underwent mitral valve replacement because of residual mitral incompetence. No hospital deaths occurred in patients who underwent mitral valve replacement. Two late deaths occurred after mitral valve replacement. Six patients had a total of 10 episodes of prosthetic valve thrombosis. Thrombolytic therapy with urokinase was successful in all episodes without serious complications. Five patients required reoperations 49 to 141 months (mean, 78.4 months) after the initial valve replacement for relative prosthetic valve obstruction as the result of somatic growth. A valve 2 or 3 sizes larger than the original prostheses was inserted without death. Actuarial survival and freedom from cardiac events at $\mathbf{1 0}$ years after the operation were $\mathbf{8 7 . 2 \%}$ and $\mathbf{7 2 . 7 \%}$ in children who underwent mitral valve repair, and $\mathbf{9 0 . 3 \%}$ and $\mathbf{6 7 . 3 \%}$ for those children who underwent mitral valve replacement. Conclusions: The current risk of mitral valve operation in the pediatric age group is low, and the long-term results are satisfactory, irrespective of severe deformation of the mitral valve apparatus and associated complex cardiac anomalies. (J Thorac Cardiovasc Surg 1999;118:99-106)
S urgery for mitral valve disease in infants and children has been a major therapeutic challenge for many years. ${ }^{1-4}$ It poses special clinical and technical difficulties that include a wide spectrum of morphologic abnormalities, ${ }^{5,6}$ a high prevalence of associated car-

From the Departments of Cardiothoracic Surgery ${ }^{\mathrm{a}}$ and Cardiology, ${ }^{\mathrm{b}}$ Kobe Children's Hospital, Kobe, Japan.

Received for publication Dec 1, 1998; revisions requested Jan 26, 1999; revisions received Feb 26, 1999; accepted for publication March 15, 1999.

Address for reprints: Naoki Yoshimura, MD, Department of Cardiothoracic Surgery, Kobe Children's Hospital, 1-1-1, Takakura-dai, Suma-ku, Kobe, 654-0081 Japan.

Copyright $(\odot) 1999$ by Mosby, Inc.

$0022-5223 / 99 \$ 8.00+0 \quad \mathbf{1 2 / 1 / 9 8 5 8 5}$ diac anomalies, ${ }^{1,7}$ and relatively small experience in each institute. ${ }^{2,4}$ However, more favorable clinical results have been obtained over the last 2 decades. ${ }^{8-10}$ In the present study, we reviewed a 20-year experience with the surgical treatment of mitral valve disease in the pediatric age group at our institution with 2 objectives: to clarify the long-term results over the last 2 decades and to evaluate the recent advances in mitral valve operation in children.

\section{Patients and methods}

Patient population. From December 1978 to September 1998, 56 patients underwent a total of 36 mitral valve repairs and 30 mitral valve replacements. Fifty-two patients had predominant mitral incompetence (MI), and 4 patients had pre- 
Table I. Associated cardiac anomalies (46 patients, 82\%)

\begin{tabular}{lc}
\hline Type of lesion & Patients $(n)$ \\
\hline Ventricular septal defect & 18 \\
Common atrioventricular canal & 9 \\
Atrial septal defect & 3 \\
Atrial septal defect + ventricular septal defect & 3 \\
Coarctation complex & 2 \\
Double outlet right ventricle & 2 \\
Aortic stenosis & 2 \\
Aortic insufficiency & 1 \\
Total anomalous pulmonary venous drainage & 1 \\
Bland-White-Garland & 1 \\
Bland-White-Garland + ventricular septal defect & 1 \\
Tricuspid atresia & 1 \\
Univentricular heart & 1 \\
Atrial septal defect + partial anomalous pulmonary & 1 \\
venous drainage &
\end{tabular}

Table II. Mitral valve lesions in patients who underwent mitral valve repair

\begin{tabular}{lr}
\hline Type of lesion & $n$ \\
\hline Supravalvular stenosing ring & 1 \\
Valve & 23 \\
$\quad$ Prolapsed leaflet & 6 \\
Cleft anterior leaflet & 1 \\
Commissure fusion & \\
Anulus & 30 \\
$\quad$ Annular dilatation & \\
Chordae & 13 \\
$\quad$ Elongated chordae & 4 \\
Short chordae & 2 \\
$\quad$ Cordal rupture & \\
Papillary muscle & 8 \\
$\quad$ Elongated papillary muscle & 3 \\
Hypertrophied or calcified papillary muscle & \\
\hline
\end{tabular}

dominant mitral stenosis. Associated cardiac anomalies were present in 46 patients (82\%; Table I). Left atrioventricular valve anomalies associated with atrioventricular discordance and the initial definitive repair of the atrioventricular canal were excluded from this study. Fourteen patients had undergone previous operations. Nine patients had undergone atrioventricular canal repair; 2 patients had undergone coarctation repair; 2 patients had undergone pulmonary artery banding, and 1 patient had undergone repair of total anomalous pulmonary venous drainage. ${ }^{11}$ Concurrent repair of associated lesions was performed in 37 patients $(66 \%)$. These included repair of complex cardiac anomalies in 3 patients, 2 of whom required total cavopulmonary anastomosis, along with a double switch operation. Cardiopulmonary bypass and systemic hypothermia $\left(12.8^{\circ} \mathrm{C}\right.$ to $\left.31.5^{\circ} \mathrm{C}\right)$ were used for all procedures. Deep hypothermic circulatory arrest was used for 6 operations before 1983. Cold blood cardioplegia with topical cardiac cooling through a median sternotomy was used in
Table III. Technique of mitral valve repair

\begin{tabular}{lc}
\hline Technique of repair & $n$ \\
\hline Resection of supravalvular stenosing ring & 1 \\
Valve & 14 \\
$\quad$ Redundant valvular tissue removal & 6 \\
$\quad$ Closure of cleft & 1 \\
$\quad$ Commissurotomy & 30 \\
Anulus & \\
$\quad$ Annuloplasty & 8 \\
Chordae & 3 \\
$\quad$ Chordal shortening & \\
$\quad$ Artificial chordae & 9 \\
Papillary muscle & \\
$\quad$ Papillary muscle shortening: split \& tuck in & 1 \\
Papillary muscle shortening: split \& basal sling & 3 \\
$\quad$ Papillary muscle splitting & \\
\hline
\end{tabular}

46 operations in which concomitant operative procedures were performed. Hypothermic ventricular fibrillation through a right lateral thoracotomy was used in 20 isolated mitral valve operations.

Mitral valve repair. The ages of the patients at the mitral valve repair ranged from 3 months to 15 years (mean $\pm \mathrm{SD}$, $3.6 \pm 3.1$ years); body weight ranged from 5.1 to $55.8 \mathrm{~kg}$ $(12.7 \pm 8.7 \mathrm{~kg})$. Seven patients were younger than 1 year of age. The pathologic findings of the mitral valve apparatus are listed in Table II. Annular dilatation was the most common anatomic lesion (30 patients), followed by prolapsed leaflet (24 patients), elongated chordae (13 patients), or papillary muscle ( 9 patients). A list of procedures is detailed in Table III. Because malformation usually implies several anomalies, several techniques were used in the same patient. Reed annuloplasty was the method of annular repair. ${ }^{12}$ Prosthetic ring annuloplasty was not used. Cleft leaflet was corrected by a direct suture technique. Prolapse of a leaflet was corrected by redundant valvular tissue removal, chordal shortening, artificial chordae, ${ }^{13}$ or papillary muscle shortening. ${ }^{8}$ More recently, we prefer the papillary muscle shortening with split and tuck-in technique (Fig 1).

Mitral valve replacement. Mitral valve replacement was indicated in patients with severe valvular deformities not amenable to repair (Fig 2). There was no difference in the prevalence of mitral valve replacement between the first and second decades (Fig 3). The age of the patients at mitral valve replacement ranged from 2 months to 16 years $(5.7 \pm 5.0$ years); body weight ranged from 4.2 to $84.7 \mathrm{~kg}(18.5 \pm 17.7$ $\mathrm{kg}$ ). Five patients were younger than 1 year of age. Prosthetic valves that were implanted included 21 St Jude Medical (17 $\mathrm{mm} \mathrm{HP}$ in 1 patient, $19 \mathrm{~mm}$ in 2 patients, $21 \mathrm{~mm}$ in 2 patients, $23 \mathrm{~mm}$ in 6 patients, $25 \mathrm{~mm}$ in 4 patients, $27 \mathrm{~mm}$ in 2 patients, $29 \mathrm{~mm}$ in 1 patient, and $33 \mathrm{~mm}$ in 2 patients; St Jude Medical, Inc, St Paul, Minn), 4 CarboMedics (25 mm in 1 patient, $27 \mathrm{~mm}$ in 2 patients, and $31 \mathrm{~mm}$ in 1 patient; Sulzer Carbomedics, Inc, Austin, Texas), 3 Björk-Shiley (17 mm, 19 mm, $23 \mathrm{~mm}$; Shiley, Inc, Irvine, Calif), and 2 ATS (23 mm, 


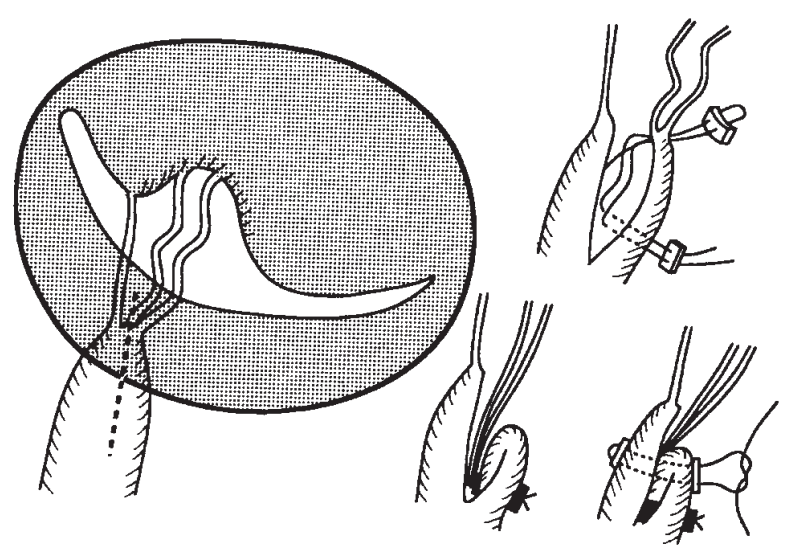

Fig 1. Papillary muscle shortening: split and tuck-in technique. The excess length of the chorda is tucked into a longitudinal split made in the top of the papillary muscle and sutured.

$29 \mathrm{~mm}$; ATS Medical, Inc, Minneapolis, Minn). The prosthesis was placed in a conventional manner within the native anulus in all patients. All patients with prosthetic valves were anticoagulated with warfarin sodium (Coumadin). The criterion for adequate anticoagulation state with warfarin was considered $15 \%$ to $35 \%$ in the thrombotest. More recently, antiplatelet agent (aspirin or dipyridamole) has been administered in combination with warfarin sodium.

Follow-up. Fifty-three operative survivors were followed through clinic visits. Two patients were lost to follow-up at 56 months and 100 months. The mean follow-up period was 92.0 months (range, 1-235 months), and the end of the follow-up study was September 30, 1998. Kaplan-Meier survival analysis was used to evaluate the survival and freedom from cardiac events. Cardiac events include cardiac death, structural and nonstructural valve dysfunction, need for reoperation, thromboembolism and bleeding, or valvular endocarditis. These events were defined in agreement with the reporting on cardiac valvular operations guidelines. ${ }^{14}$

\section{Results}

\section{Early results}

Mitral valve repair. Two hospital deaths (5.6\%) occurred in patients who underwent mitral valve repair. An 11-month-old infant who underwent an operation in 1980 died of multiple organ failure caused by mediastinitis. The second death was in an infant with active infective endocarditis who underwent mitral valve repair on an emergency basis for progressive heart failure. This patient died of sepsis and disseminated intravascular coagulation on postoperative day 9. One patient who underwent mitral annuloplasty, triangular resection of the anterior leaflet, and shortening of the papillary muscle with concomitant closure of ventricu-

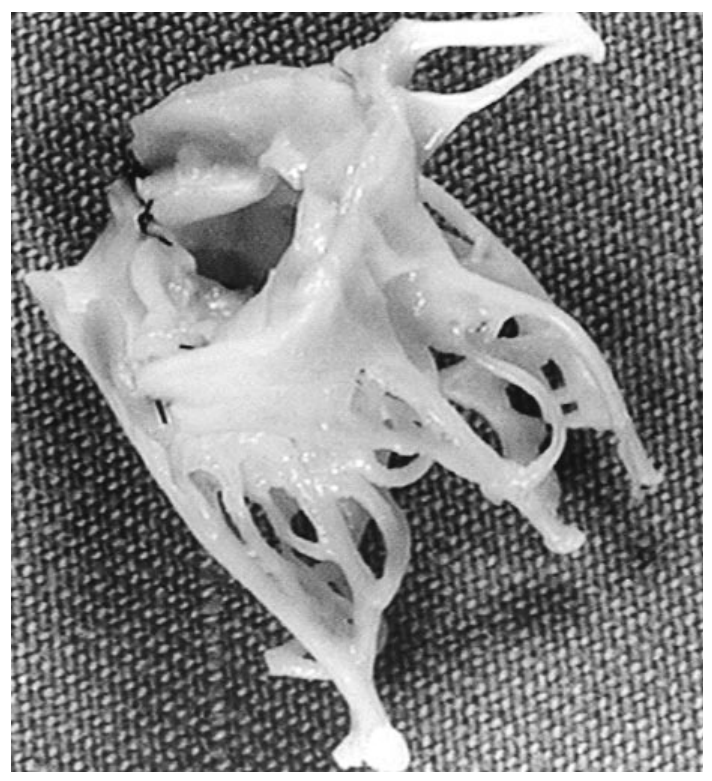

Fig 2. A rare case with supravalvular stenosing ring and papillary muscle agenesis. In patients with gross deformities of the mitral valve apparatus in which no conservative surgical treatment is feasible, mitral valve replacement should be considered the procedure of choice.

lar septal defect had severe residual $\mathrm{MI}$ and required valve replacement 56 days after the reparative operation. Among patients not having reoperation, cardiac catheterization was performed in 28 patients before discharge from hospital. Left ventriculogram showed grade $2 \mathrm{MI}$ in 3 patients and grade 1 in 12 patients. The other 13 patients had no MI.

Mitral valve replacement. No hospital deaths occurred in this series. All patients who underwent valve replacement had marked clinical improvement and relief of congestive heart failure. Unilateral thrombosed leaflet of a bileaflet mechanical valve occurred in 5 patients before discharge from the hospital (Table IV). A 5-month-old infant showed signs of low cardiac output 17 days after the mitral valve replacement; the other 4 patients were asymptomatic and were diagnosed during routine checkup. Thrombolytic therapy with urokinase was performed each time, and the thrombus was successfully dissolved. Initial dose of urokinase ranged from 500 to $18,000 \mathrm{U} / \mathrm{kg} / \mathrm{hr}$, and maximum dose ranged from 2600 to $18,000 \mathrm{U} / \mathrm{kg} / \mathrm{hr}$. The duration of treatment ranged from 8 to 14 days. Four patients experienced bleeding complications, and 1 patient required blood transfusion during the thrombolytic therapy. Two of the 5 patients with complicated unilateral thrombosed leaflet showed poor left ventric- 


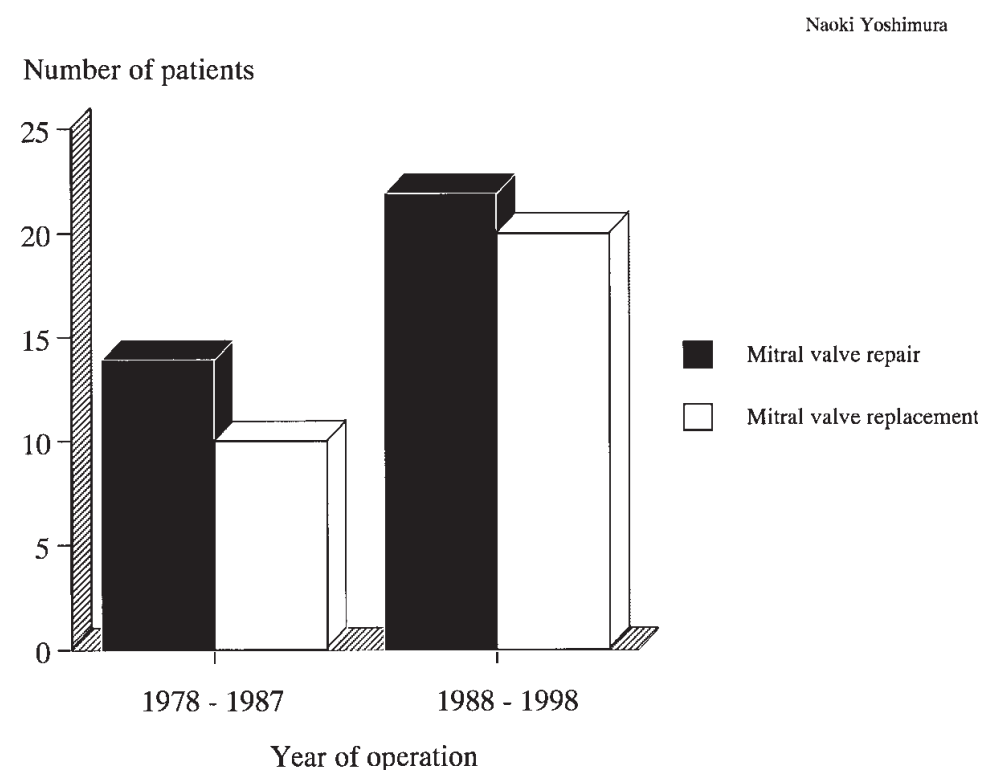

Fig 3. The numbers of mitral valve repair and mitral valve replacement by operation year.

Table IV. Thrombolytic therapy for the prosthetic valve thrombosis

\begin{tabular}{|c|c|c|c|c|c|c|c|}
\hline Patient & $\begin{array}{l}\text { Age at } \\
M V R\end{array}$ & Prosthesis & $\begin{array}{c}\text { Time from } \\
\text { MVR } \\
\text { to event }\end{array}$ & $\begin{array}{c}\text { Clinical } \\
\text { presentation }\end{array}$ & $\begin{array}{c}\text { Maximum dos } \\
\text { of } U K \\
(U / \mathrm{kg} / \mathrm{hr})\end{array}$ & $\begin{array}{l}\text { Duration of } \\
\text { treatment }(d)\end{array}$ & Complications \\
\hline 1 & $9 y$ & SJM (33 mm) & $7 \mathrm{mo}$ & Cerebellar infarction & 1,000 & 5 & No \\
\hline \multirow[t]{3}{*}{2} & $1 \mathrm{y}$ & SJM (23 mm) & $11 \mathrm{~d}$ & Asymptomatic & 2,600 & 10 & Hematuria \\
\hline & & & $13 \mathrm{mo}$ & Vomiting & 2,900 & 13 & Subcutaneal hemorrhage \\
\hline & & & $29 \mathrm{mo}$ & New murmur & 1,700 & 10 & No \\
\hline 3 & $5 \mathrm{~m}$ & SJM (19 mm) & $17 \mathrm{~d}$ & LOS & 18,000 & 10 & Hematoma; blood transfusion \\
\hline \multirow[t]{3}{*}{4} & $3 y$ & $\mathrm{SJM}(25 \mathrm{~mm})$ & $1 \mathrm{mo}$ & Asymptomatic & 4,000 & 8 & Subcutaneal hemorrhage \\
\hline & & & $2 \mathrm{mo}$ & Asymptomatic & 3,000 & 12 & No \\
\hline & & & $3 \mathrm{mo}$ & Asymptomatic & 2,000 & 4 & No \\
\hline 5 & $4 y$ & $\mathrm{CM}(25 \mathrm{~mm})$ & $1 \mathrm{mo}$ & Asymptomatic & 3,000 & 12 & No \\
\hline 6 & $5 y$ & ATS (23 mm) & $26 \mathrm{~d}$ & Asymptomatic & 10,500 & 14 & $\begin{array}{l}\text { Subcutaneal hemorrhage; } \\
\text { nasal bleeding }\end{array}$ \\
\hline
\end{tabular}

MVR, Mitral valve replacement; SJM, St Jude Medical; LOS, low cardiac output syndrome; CM, Carbomedics; ATS, ATS Medica; UK, urokinase.

ular function (left ventricular ejection fraction, $49.2 \%$ and $43.5 \%)$.

\section{Late results}

Mitral valve repair. There were 2 late deaths among the 33 patients who survived the initial mitral valve repair. One patient who underwent valve replacement 56 days after the reparative operation died of prosthetic valve dysfunction. Death occurred 13 months after mitral valve replacement. Another patient died of chronic renal failure 28 months after mitral valve repair. Actuarial survival was $87.2 \%$ (95\% confidence limits [CL], $75.3 \%-99.1 \%$ ) at 10 years in children who underwent mitral valve repair (Fig 4).
Reoperation was performed in 3 patients. Two of these patients underwent mitral valve replacement because of residual MI 3 and 64 months after the reparative operation, respectively. Another patient who underwent mitral annuloplasty, triangular resection of the anterior leaflet, and closure of ventricular septal defect experienced the development of mitral stenosis. The patient required open mitral commissurotomy and mitral valve replacement 43 and 141 months after the initial operation, respectively. Among the long-term survivors without reoperation, 8 patients had a grade $1 / 6$ or $2 / 6$ systolic murmur. Echocardiography showed trivial to mild MI. All surviving patients were free of 
$(\%)$

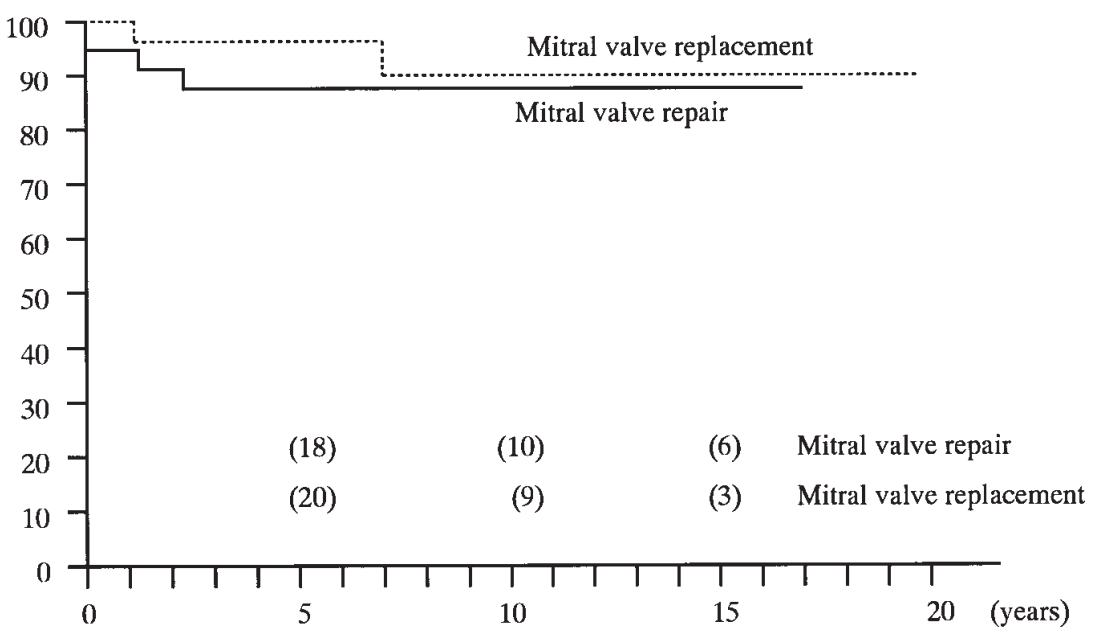

Fig 4. Actuarial survival (including hospital deaths) of patients who underwent mitral valve repair (solid line) and mitral valve replacement (dotted line).

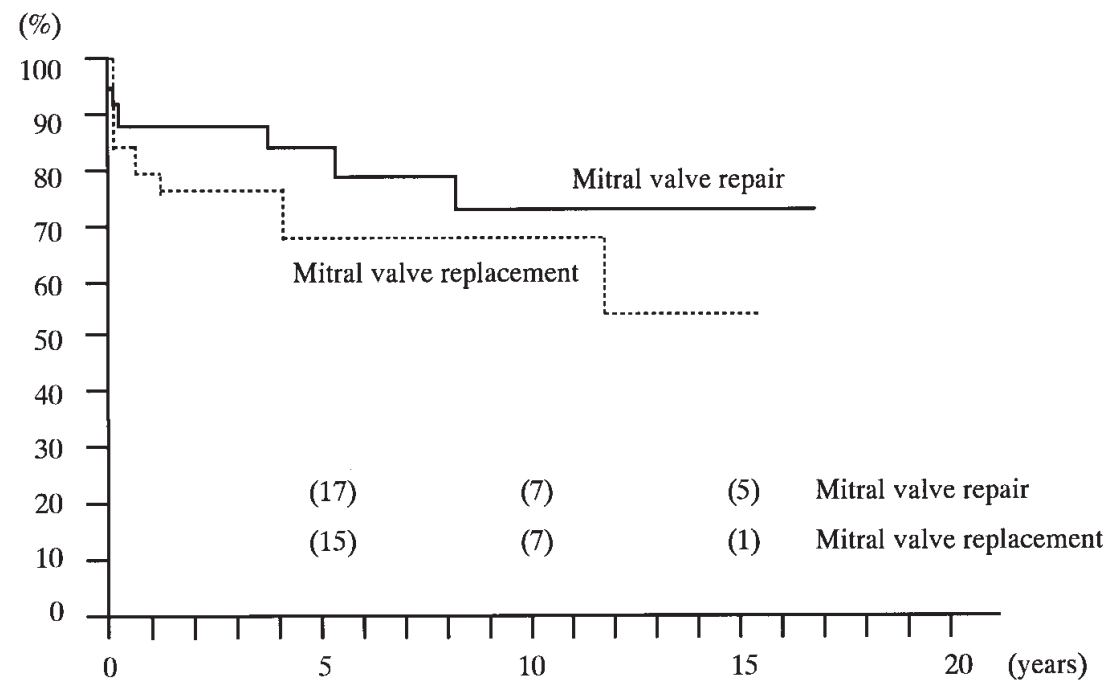

Fig 5. Freedom from cardiac events (including hospital deaths and morbidity) of patients who underwent mitral valve repair (solid line) and mitral valve replacement (dotted line).

symptoms. Actuarial freedom from cardiac events was $72.7 \%$ (95\% CL, 54.0\%-91.5\%) at 10 years in children who underwent mitral valve repair (Fig 5).

Mitral valve replacement. There were 2 late deaths as a result of prosthetic valve dysfunction in 1 patient (mentioned previously) and sepsis in another patient. Deaths occurred from 14 to 83 months after mitral valve replacement. Actuarial survival was $90.3 \%$ (95\% $\mathrm{CL}, 77.0 \%-100 \%)$ at 10 years in children who underwent mitral valve replacement (Fig 4).
Among the 25 patients who underwent mitral valve replacement, 5 patients outgrew their prosthetic valve and underwent a repeat valve replacement $49,49,56$, 97, and 141 months after the initial valve replacement, respectively. The age, body weight, body surface area, and prosthetic valve size at the initial and second valve replacements are shown in Table V. Two of the 5 patients underwent initial valve replacement at the age of less than 1 year with the use of a 19-mm BjörkShiley prosthesis (Shiley, Inc) and a 19-mm St Jude 
Table V. Redo mitral valve replacement

\begin{tabular}{|c|c|c|c|c|}
\hline Patient & Age & $\begin{array}{l}\text { Body weight } \\
\quad(\mathrm{kg})\end{array}$ & $\begin{array}{c}\text { Body surface area } \\
\qquad\left(m^{2}\right)\end{array}$ & Prosthesis \\
\hline 1 & $6 \mathrm{~m} \rightarrow 4 \mathrm{y} 7 \mathrm{~m}$ & $5.3 \rightarrow 14.2$ & $0.30 \rightarrow 0.66$ & B-S $(19 \mathrm{~mm}) \rightarrow$ SJM $(25 \mathrm{~mm})$ \\
\hline 2 & $1 \mathrm{y} \rightarrow 5 \mathrm{y} 2 \mathrm{~m}$ & $6.7 \rightarrow 16.1$ & $0.35 \rightarrow 0.67$ & $\mathrm{~B}-\mathrm{S}(17 \mathrm{~mm}) \rightarrow \mathrm{SJM}(21 \mathrm{~mm})$ \\
\hline 3 & $4 \mathrm{y} 6 \mathrm{~m} \rightarrow 16 \mathrm{y} 3 \mathrm{~m}$ & $14.9 \rightarrow 84.7$ & $0.69 \rightarrow 1.93$ & $\mathrm{SJM}(23 \mathrm{~mm}) \rightarrow \mathrm{CM}(27 \mathrm{~mm})$ \\
\hline 4 & $3 \mathrm{y} \rightarrow 11 \mathrm{y} 1 \mathrm{~m}$ & $11.9 \rightarrow 42.3$ & $0.56 \rightarrow 1.28$ & $\operatorname{SJM}(25 \mathrm{~mm}) \rightarrow \operatorname{ATS}(29 \mathrm{~mm})$ \\
\hline 5 & $5 \mathrm{~m} \rightarrow 5 \mathrm{y} 1 \mathrm{~m}$ & $5.5 \rightarrow 14.2$ & $0.33 \rightarrow 0.63$ & $\operatorname{SJM}(19 \mathrm{~mm}) \rightarrow \operatorname{ATS}(23 \mathrm{~mm})$ \\
\hline
\end{tabular}

$B$-S, Björk-Shiley; SJM, St Jude Medical; CM, Carbomedics; ATS, ATS Medical.

Medical prosthesis (St Jude Medical, Inc). The body surface area of the 2 patients doubled from 0.30 and $0.33 \mathrm{~m}^{2}$ at the initial operation to 0.66 and $0.63 \mathrm{~m}^{2}$ at the time of repeat valve replacement. In 4 patients a valve 2 sizes larger and in 1 patient a valve 3 sizes larger than the original prostheses were inserted (Table V). Second valve replacement was safely performed with no deaths.

Unilateral thrombosed leaflet of a bileaflet prosthesis occurred in 3 patients between 2 and 29 months after operation (Table IV). These 3 patients underwent anticoagulation with warfarin and antiplatelet agents and were maintained by the thrombotest between $20 \%$ and $30 \%$. Thrombolytic therapy with urokinase was performed as the first line of treatment for a thrombosed valve. Maximum dose ranged from 1000 to 3000 $\mathrm{U} / \mathrm{kg} / \mathrm{hr}$, and the duration of treatment ranged from 5 to 13 days. A transient subcutaneous hemorrhage occurred in 1 patient during the thrombolytic therapy. Successful thrombolysis was achieved in these 3 patients, and none of these patients required subsequent operation. Actuarial freedom from cardiac events was $67.3 \%$ (95\% CL, $49.3 \%-85.2 \%)$ at 10 years in children who underwent mitral valve replacement (Fig 5).

\section{Discussion}

This report describes our 20-year experience with operations for mitral valve disease in children in an attempt to assess the clinical course of patients in terms of valve-related problems in this special age group. There have been several reports of operations for congenital mitral valve malformations in the pediatric age group. ${ }^{1-4,7-10}$ Early and late deaths in small children with mitral valve disease has been high, particularly for those children with valve replacement. ${ }^{4,15,16}$ Kadoba and coworkers ${ }^{15}$ reported 9 early deaths in 25 patients $(36 \%)$ with mitral valve replacement in the first year of life. Zweng and coworkers ${ }^{4}$ described the results of mitral valve replacement in 19 children younger than 5 years of age. There were 6 early deaths (32\%) and 3 late deaths $(16 \%)$. This special age group of patients poses unique problems that include the small size of mitral anulus, a wide spectrum of valvular lesions and relatively small experience, ${ }^{4-6}$ a high prevalence of associated cardiac anomalies that often complicate the perioperative course, ${ }^{1,7}$ a relative stenosis of the prosthesis as the result of tissue overgrowth or somatic growth, ${ }^{15-18}$ and difficulties associated with anticoagulant therapy. ${ }^{19}$ Although surgical management of congenital malformations of the mitral valve in the pediatric age group remain a therapeutic challenge, especially in patients with mitral stenosis or infants younger than 1 year of age described in series by Kadoba and colleagues ${ }^{15}$ and Zweng and colleagues, ${ }^{4}$ recent reports of mitral valve operation in the pediatric age group have been encouraging, with decreased morbidity and early and late deaths. ${ }^{8-10}$ Because limited information is available concerning the recent advances in mitral valve operation in children, we reviewed our institutional experience with mitral valve operation in children over the past 2 decades. The early mortality rate was $3.6 \%$ (2/56 patients), and the late mortality rate was $5.6 \%$ (3/54 patients, including 2 patients with noncardiac death). Our experience demonstrates that the current operative risk of mitral valve operation is low, irrespective of severe deformation of the mitral valve apparatus and associated complex cardiac anomalies.

Mitral valve repair was initially performed in 35 of 56 patients. Long-term results compare favorably with those after mitral valve replacement. Mitral valve repair offers the advantages of the avoidance of thromboembolism, the preservation of chordal function, and a potentially reduced need for reoperation. Because of the wide spectrum of lesions, which characteristically involved multiple components of the valvular apparatus, ${ }^{5}$ multiple techniques of valve repair are required..$^{1,8,9,13}$ In the present study, annular dilatation and prolapsed leaflet were the most frequent lesions. Annuloplasty was performed in all patients with annular dilatation irrespective of mitral valve disease. The method of annular repair consisted of Reed annuloplasty. ${ }^{12}$ No rigid rings were used so as not to interfere 
with the growth of the heart and to avoid thromboembolism. We presently treat mitral valve prolapse by redundant valvular tissue removal, artificial chordae, ${ }^{13}$ and/or papillary muscle shortening with the split and tuck-in technique. These techniques provided symptomatic relief and long-term durability of the results in most of the patients.

Although conservative procedures are obviously preferable and should be considered the procedures of choice, morphologic condition greatly influences the difficulty of conservative surgical treatment for congenital mitral valve disease in the pediatric age group. We encountered many valves significantly lacking in valve tissue and also having other severe deformation of the subvalvular apparatus that rendered reconstruction impossible. ${ }^{20}$ In patients with gross deformities of the mitral valve apparatus in which no conservative surgical treatment is feasible, mitral valve replacement should be considered the procedure of choice. In our experience, mitral valve replacement in children can be performed safely with no hospital death. Although prosthetic valve replacement was not associated with any operative deaths in this series, the major problems with valve replacement in children are long-term survival and valve-related complications. ${ }^{15-17,21}$

Mitral valve replacement in children carries the disadvantage of requiring repeat valve replacement. ${ }^{15-16} \mathrm{In}$ our experience, 5 patients required reoperations for relative prosthetic valve obstruction because of somatic growth. It is well known that the anulus of the mitral valve will grow even when fixed to a prosthetic valve sewing ring, thereby permitting the use of a largersized valve at the time of repeat valve replacement. ${ }^{15,16,18} \mathrm{~A}$ valve 2 or 3 sizes larger than the original prostheses was inserted in our patients. Indications and timing for repeat valve replacement have not been established. Kadoba and associates ${ }^{15}$ performed repeat mitral valve replacement on several patients with complicated acute pulmonary edema or circulatory collapse on an emergency basis. We consider it essential that the prosthetic valve function and hemodynamic parameters are re-evaluated when the body surface area of the patients achieve twice that at the initial operation especially in patients in whom mitral valve replacement was performed before the age of 1 year. We believe that elective second valve replacement can be performed safely and provide extended palliation for many years.

Prosthetic valve thrombosis is one of the most frequent complications after valve replacement operation. ${ }^{19,21}$ A second surgical procedure with debridement or valve replacement has been the traditional method of management. Since Luluaga and colleagues ${ }^{22}$ first reported the successful treatment of a prosthetic valve thrombosis in the tricuspid position with thrombolytic therapy, several cases receiving thrombolytic therapy have been reported, and this approach has become a promising alternative to valve replacement. ${ }^{23-26}$ However, to our knowledge, no series of thrombolytic therapy as first-line therapy for prosthetic valve thrombosis in the pediatric age group has been reported. Since our first experience with thrombolytic treatment of a thrombosed St Jude Medical valve, we have used this approach as our first-line therapy for prosthetic valve thrombosis. Since 1990, 6 patients had a total of 10 episodes of prosthetic valve thrombosis. The incidence of prosthetic valve thrombosis for patients who underwent operation in our institution is relatively high, probably because a larger-sized prosthesis was implanted in children in consideration of their somatic growth. Thrombus formation may occur easily because blood flow through the prosthesis is low in children. Poor left ventricular function might be one of the causative factors of prosthetic valve thrombosis. However, most patients could be stabilized hemodynamically because large-sized bileaflet prostheses continued to allow blood flow, which could avoid an emergency operation or sudden death and provide time for an accurate diagnosis. Diagnosis was established, and the treatment was monitored by echocardiography and cinefluoroscopy. All patients were treated with a urokinase loading dose of about 2500 to $3500 \mathrm{U} / \mathrm{kg} / \mathrm{hr}$. If necessary, the infusion was subsequently increased to a maximum dose of $18,000 \mathrm{U} / \mathrm{kg} / \mathrm{hr}$. Joyce and colleagues ${ }^{25}$ reported that children required a larger dose of urokinase than that required for adults because plasminogen levels are lower in children. Thrombolytic therapy was successful in all episodes without serious complications. We believe that thrombolytic therapy can be used as the first-line therapy in children with prosthetic valve thrombosis.

In summary, we reviewed a 20-year experience with the surgical treatment of mitral valve disease in the pediatric age group at our institution. Thirty-six mitral valve repairs were performed in 35 patients. Two early deaths occurred in patients younger than 1 year of age. Actuarial survival and freedom from cardiac events at 10 years were $87.2 \%$ and $72.7 \%$, respectively. Although mitral valve repair should be considered the procedure of choice, mitral valve replacement should be considered as the procedure of choice in patients with gross deformities of the mitral valve apparatus. Thirty mitral valve replacements in 25 children were performed safely with no hospital deaths. Actuarial survival and freedom from cardiac events at 10 years were $90.3 \%$ and 
$67.3 \%$, respectively. Thus we conclude that the current operative risk of mitral valve operation is low, irrespective of severe deformation of the mitral valve apparatus and associated complex cardiac anomalies.

\section{REFERENCES}

1. Carpentier A, Branchini B, Cour JC, Asfaou E, Villani M, Deloche A, et al. Congenital malformations of the mitral valve in children: pathology and surgical treatment. J Thorac Cardiovasc Surg 1976;72:854-66.

2. Coles JG, Williams WG, Watanabe T, Duncan KF, Sherret H, Dasmahapatra HK, et al. Surgical experience with reparative techniques in patients with congenital mitral valvular anomalies. Circulation 1987;76(suppl):III117-22.

3. Stellin G, Bortolotti U, Mazzuucco A, Faggian G, Guerra F, Daliento L, et al. Repair of congenitally malformed mitral valve in children. J Thorac Cardiovasc Surg 1988;95:480-5.

4. Zweng TN, Bluett MK, Mosca R, Callow LB, Bove EL. Mitral valve replacement in the first 5 years of life. Ann Thorac Surg 1989;47:720-4

5. Davachi F, Moller JH, Edwards JE. Disease of the mitral valve in infancy: an anatomic analysis of 55 cases. Circulation 1971;43: 565-79.

6. Oosthoek PW, Wenink ACG, Wisse LJ, Gittenberger-de Groot AC. Development of the papillary muscles of the mitral valve: morphogenetic background of parachute-like asymmetric mitral valves and other mitral valve anomalies. J Thorac Cardiovasc Surg 1998;116:36-46.

7. Okita Y, Miki S, Kusuhara K, Ueda Y, Tahata T, Tsukamoto Y, et al. Early and late results of reconstructive operation for congenital mitral regurgitation in pediatric age group. J Thorac Cardiovasc Surg 1988;96:294-8.

8. Aharon AS, Laks H, Drinkwater DC, Chugh R, Gates RN, Grant $\mathrm{PW}$, et al. Early and late results of mitral valve repair in children. J Thorac Cardiovasc Surg 1994;107:1262-71.

9. Uva MS, Galletti L, Gayet FL, Piot D, Serraf A, Bruniaux J, et al. Surgery for congenital mitral valve disease in the first year of life. J Thorac Cardiovasc Surg 1995;109:164-76.

10. Chauvaud S, Fuzellier JF, Houel R, Berrebi A, Mihaileanu S, Carpentier A. Reconstructive surgery in congenital mitral valve insufficiency (Carpentier's techniques): long-term results. J Thorac Cardiovasc Surg 1998;115:84-93.

11. Yamaguchi M, Ohashi H, Imai M, Oshima Y, Hosokawa Y. Congenital mitral regurgitation associated with total anomalous pulmonary venous drainage: report of a rare combination. J Cardiovasc Surg 1991;32:278-80.
12. Reed GE, Tice DA, Clauss RH. Asymmetric exaggerated mitral annuloplasty: repair of mitral insufficiency with hemodynamic predictability. J Thorac Cardiovasc Surg 1965;49:752-61.

13. Murakami T, Yagihara T, Yamamoto F, Uemura H, Yamashita K, Ishizaka T. Artificial chordae for mitral valve reconstruction in children. Ann Thorac Surg 1998;65:1377-80.

14. Edmunds LH, Clark RE, Cohn LH, Grunkemeier GL, Miller DC, Weisel RD. Guideline for reporting morbidity and mortality after cardiac valvular operations. Ann Thorac Surg 1996;62:932-5.

15. Kadoba K, Jonas RA, Mayer JE, Castaneda AR. Mitral valve replacement in the first year of life. J Thorac Cardiovasc Surg 1990;100:762-8.

16. Gardner TJ, Roland JMA, Neill CA, Donahoo JS. Valve replacement in children: a fifteen-year perspective. J Thorac Cardiovasc Surg 1982;83:178-85.

17. Borkon AM, Soule L, Reitz BA, Gott VL, Gardner TJ. Five year follow-up after valve replacement with the St Jude Medical valve in infants and children. Circulation 1986;74(suppl):I110-5 .

18. Nudelman I, Schachner A, Levy MJ. Repeated mitral valve replacement in the growing child with congenital mitral valve disease. J Thorac Cardiovasc Surg 1980;79:765-9.

19. Bradley LM, Midgley FM, Watson DC, Getson PR, Scott LP. Anticoagulation therapy in children with mechanical prosthetic cardiac valves. Am J Cardiol 1985;56:533-5.

20. Yamaguchi M, Ohashi H, Hosokawa Y, Tachibana H, Wakita N, Mito H. Mitral valve replacement in infancy. Nippon Kyobu Geka Gakkai Zasshi 1986;34:1040-7.

21. Harada Y, Imai Y, Kurosawa H, Ishihara K, Kawada M, Fukuchi S. Ten-year follow-up after valve replacement with the St. Jude Medical prosthesis in children. J Thorac Cardiovasc Surg 1990; 100:175-80.

22. Luluaga IT, Carrera D, D'Oliveira J, Cantaluppi CG, Santin H, Molteni L. Successful thrombolytic therapy after acute tricuspid valve obstruction [letter]. Lancet 1971;1:1067-8.

23. Silber H, Khan SS, Matloff JM, Chaux A, DeRobertis M, Gray R. The St. Jude valve: thrombolysis as the first line of therapy for cardiac valve thrombosis. Circulation 1993;87:30-7.

24. Munclinger MJ, Patel JJ, Mitha AS. Thrombolysis of thrombosed St. Jude Medical prosthetic valves: rethrombosis: a sign of tissue ingrowth. J Thorac Cardiovasc Surg 1998;115:248-9.

25. Joyce LD, Boucek M, McGough EC. Urokinase therapy for thrombosis of tricuspid prosthetic valve. J Thorac Cardiovasc Surg 1983;85:935-7.

26. Manteiga R, Souto JC, Altes A, Mateo J, Aris A, Dominguez JM, et al. Short-course thrombolysis as the first line of therapy for cardiac valve thrombosis. J Thorac Cardiovasc Surg 1998;115:780-4. 